\title{
IMPLICAÇÕES SIMBÓLICAS NA ORGANIZAÇÃO DE UM HOME CARE: INTERPRETAÇÕES ENTRE A EQUIPE DE SAÚDE E OS CUIDADORES FAMILIARES
}

\author{
Marianne Viana Borges * \\ mborges@unimedvx.com.br \\ Alfredo Rodrigues Leite da Silva* \\ alfredoufes@gmail.com \\ Eloísio Moulin de Souza* \\ eloisiomoulin@gmail.com \\ Letícia Dias Fantinel* \\ leticiafantinel@gmail.com \\ *Universidade Federal do Espírito Santo - Vitória, ES / Brasil
}

http://dx.doi.org/10.1590/1413-2311.102014.53644

Recebido em 20/02/2015

Aprovado em 24/03/2016

Disponibilizado em 06/06/2016

Avaliado pelo sistema "double blind review"

Revista Eletrônica de Administração

Editora-chefe: Aurora Zen

ISSN 1413-2311 (versão "on line")

Editada pela Escola de Administração da Universidade Federal do Rio Grande do Sul.

Periodicidade: Quadrimestral

Sistema requerido: Adobe Acrobat Reader

\section{RESUMO}

O objetivo deste artigo é compreender as implicações simbólicas na organização de um home care em torno das práticas dos cuidadores familiares e da equipe de saúde. Utiliza-se uma perspectiva simbólica para desvendar símbolos resultantes de interações sociais presentes no dia-a-dia do grupo estudado, de forma a possibilitar a compreensão de seus significados. A pesquisa empírica realizada foi de cunho qualitativo e descritivo. Os dados foram coletados por meio de sete entrevistas semiestruturadas com os cuidadores familiares dos pacientes e três grupos focais com 27 profissionais do home care de uma empresa de saúde privada. Após a transcrição das entrevistas e dos grupos focais, os dados obtidos foram agrupados e categorizados por meio da análise de conteúdo de modelo misto. Os resultados indicam que interpretações de aspectos simbólicos interferem na avaliação e operação do atendimento domiciliar em oposição ao hospitalar. Elas levam à reconstrução social dos simbolismos dos familiares, porque se inserem em um novo contexto adverso (a doença), a despeito de permanecerem em um contexto conhecido (o lar). Nessa reconstrução, as práticas dos atores organizacionais envolvidos se legitimam ou são rejeitadas; portanto, cabe reconhecer tal dinâmica na preparação das equipes de profissionais para atuarem no serviço de home care. 


\title{
IMPLICAÇÕES SIMBÓLICAS NA ORGANIZAÇÃO DE UM HOME CARE: INTERPRETAÇÕES ENTRE A EQUIPE DE SAÚDE E OS CUIDADORES FAMILIARES
}

Palavras-Chave: Assistência Domiciliar; Simbolismo; Prática; Cuidador Familiar; Equipe de Assistência ao Paciente.

\section{SYMBOLISM AND PRACTICES IN A HOME CARE SERVICE: BETWEEN STAFF AND FAMILY CAREGIVERS}

\begin{abstract}
The purpose of this article is to understand the social implication in the organizing of a home care services around the practices of family caregivers and home care team. We used a symbolic perspective to unravel symbols resulting from social interactions that occurred on the everyday life of the group in order to better understand their meanings. The empirical research was qualitative and descriptive. The data was collected using semi-structured interviews with seven family caregivers and three focus groups with twenty seven home care professionals of a private health company. After transcribing the interviews and focus groups, the data were grouped and categorized by mixed model content analysis. The results show that the interpretations of symbolic aspects interfere in evaluation in opposition to hospital. They conduct the interviewers to a social reconstruction of the family symbolism, in the way it is inserted in an adverse context (the disease), despite partly remain in a family context (home). It is within the dynamics of this reconstruction that practices of the organizational actors are legitimize or rejected, then, must be recognized this dynamic in the professionals training to work in the home care service.
\end{abstract}

Keywords: Home Care; Symbolism; Practice; Family Caregiver; Patient Care Team.

\section{IMPLICACIONES SIMBÓLICAS EN LA ORGANIZACIÓN DE UNA ORGANIZACIÓN DE CUIDADO A DOMICILIO: ENTRE EL EQUIPO DE SALUD Y LOS CUIDADORES FAMILIARES}

\begin{abstract}
RESUMEN
El objetivo de este trabajo es entender las implicaciones simbólicas para la organización de una organización de cuidado a domicilio en torno a las prácticas de los cuidadores familiares y el equipo de salud. Utilizamos una perspectiva simbólica para desvelar los símbolos resultantes de las interacciones sociales y existentes en el día a día del grupo de estudio con el fin de obtener una mejor comprensión de sus significados. La investigación empírica fue cualitativa y descriptiva. Los datos fueron recolectados a través de entrevistas semiestructuradas con siete cuidadores familiares de pacientes y tres grupos focales con 27 profesionales en la atención domiciliaria de una empresa de salud privada. Después de transcribir las entrevistas y grupos focales, los datos fueron agrupados y clasificados con análisis de contenido del modelo mixto. Los resultados indican que las interpretaciones de aspectos simbólicos interfieren en la evaluación y el funcionamiento del cuidado a domicilio en oposición al tradicional cuidado en hospital. Conducen a la reconstrucción del simbolismo social de la familia, porque operan en un nuevo entorno adverso (enfermedad),

REAd | Porto Alegre - Edição 83 - No 1 - Janeiro/Abril 2016 - p. 52-76
\end{abstract}


independientemente de permanecer en un ambiente familiar (hogar). En esta reconstrucción, las prácticas de los actores organizacionales legitimar o se rechazan; por lo tanto, debemos reconocer esta dinámica en la preparación de los profesionales para trabajar en el servicio de atención domiciliaria.

Palabras Clave: Atención Domiciliaria; Simbolismo; Práctica; Cuidador familiar; Grupo de Atención al Paciente.

\section{INTRODUÇÃO}

O objetivo deste artigo é compreender as implicações simbólicas na organização de um home care em torno das práticas dos cuidadores familiares e da equipe de saúde. $\mathrm{O}$ estudo se legitima no entendimento de que, nas últimas décadas, tem sido crescente a busca por alternativas de organização que aliem a racionalização da utilização de leitos hospitalares de alto custo e a nova lógica de humanização da assistência à saúde (SILVA, SENA, LEITE et al., 2005). A assistência domiciliar ou home care é entendida, assim, como uma opção alinhada às necessidades contextuais citadas.

A organização da assistência domiciliar é desenvolvida no ambiente do domicílio por uma equipe interprofissional e ocorre de acordo com as particularidades e necessidades apresentadas pelo paciente, seus familiares, bem como por todo o contexto que circunda esse domicílio (LACERDA, OLINISKI, GIACOMOZZI et al., 2007). Além da equipe interprofissional de saúde, as famílias são parte integrante dessa organização que, apesar de ocorrer na residência familiar, não pertence à família, compondo assim uma organização com características consideradas incomuns.

Tendo em vista esse contexto, a adoção do home care leva ao desafio gerencial de operacionalizar uma organização na qual, em uma residência, as práticas familiares passam a ser articuladas com as práticas típicas de uma organização hospitalar. Dentre os vários aspectos que envolvem essas articulações, os simbolismos familiares e organizacionais medeiam as interpretações entre os membros familiares, os cuidadores e a equipe interprofissional, em torno das práticas sociais dos sujeitos no serviço de home care. A compreensão dessas interpretações e implicações possibilita a busca de caminhos para que profissionais, cuidadores e familiares envolvidos contribuam para a própria realização do serviço. Com base nesse entendimento, o presente artigo trata do seguinte problema de 


\section{IMPLICAÇÕES SIMBÓLICAS NA ORGANIZAÇÃO DE UM HOME CARE: INTERPRETAÇÕES ENTRE A EQUIPE DE SAÚDE E OS CUIDADORES FAMILIARES}

pesquisa: como os simbolismos organizacionais envolvem a organização de um home care em torno das práticas dos cuidadores familiares e da equipe de saúde?

Para problematizar essa questão, adotou-se a concepção de simbolismo organizacional na ótica interpretativista (MORGAN; FROST; PONDY, 1983), segundo a qual o simbolismo consiste na prática da representação subjetiva de um signo com conotação maior do que ele próprio, por ser dotado de significados e remeter a distintas interpretações. Tais interpretações são tratadas em suas relações com representações sociais construídas no cotidiano dos sujeitos (DOISE, 2002; MOSCOVICI, 2003). Os dados empíricos, confrontados com as contribuições teóricas, foram obtidos por meio de uma estratégia qualitativa de pesquisa. A coleta de dados se deu por meio de sete entrevistas semiestruturadas com os cuidadores familiares dos pacientes atendidos na modalidade de internação domiciliar e três grupos focais com 27 profissionais assistenciais do home care de uma empresa de saúde privada. Para o tratamento dos dados, utilizou-se a análise de conteúdo.

Com a finalidade de desenvolver tal discussão, o artigo foi organizado da seguinte maneira: primeiramente, encontra-se a discussão teórica organizada em dois tópicos. Em seguida, são apresentados os aspectos metodológicos da investigação empírica. Ao final, os dados empíricos são analisados e discutidos e, por fim, apresentam-se as considerações finais do artigo.

\section{AS ORGANIZAÇÕES DE SAÚDE E O HOME CARE}

Uma das premissas da atuação em serviços de home care é a imposição de exigências especiais por parte das organizações que visam a atender a permanentes e complexas necessidades do setor, em que casos supostamente simples podem comportar riscos não presumíveis (PITTA, 1996). O home care insere-se em um sistema de saúde constituído por unidades que promovem diferentes níveis de cuidado (ERDMANN, MELLO, MEIRELLES et al., 2004), como uma modalidade que consiste em encaminhar para o tratamento domiciliar o paciente clinicamente estável (DUARTE; DIOGO, 2005), com necessidades formalmente avaliadas (GENET, 2001), assistindo ao indivíduo e à família de forma integral e contextualizada (KERBER; KIRCHHOF; CEZAR-VAZ, 2008).

REAd | Porto Alegre - Edição 83 - N 1 - Janeiro/Abril 2016 - p. 52-76 
Esse modelo tem se destacado devido a fatores de ordem técnica, econômica, social e cultural. Ressalta-se a mudança demográfica na pirâmide populacional, a mudança de paradigma do sistema de saúde mundial (ênfase nos pacientes crônicos), a busca por redução de custos e de riscos de infecção, a tentativa de liberação de leitos hospitalares, a expectativa de maior envolvimento do paciente com a família e de atendimento mais humanizado (DUARTE; DIOGO, 2005; SILVA, SENA, LEITE et al., 2005).

A assistência domiciliar é também resposta à demanda de pacientes com doenças crônicas (DAL BEN; GAIDZINSKI, 2007). Construídos socialmente, os significados normalmente atribuídos a diferentes doenças podem estar presentes nessa ambiência, embebendo o espaço do cuidado domiciliar com diversas representações sobre o que seria estar doente e o que se caracterizaria como necessário ao paciente. A metáfora da doença, muitas vezes associada a punições sobrenaturais, condições psicológicas ou até mesmo "síntese do mal" (SONTAG, 1984, p. 53), pode impedir que a condição do paciente seja discutida abertamente, fazendo com que concepções fantasiosas ou mistificadoras predominem na compreensão dos que cercam o doente (SONTAG, 1984).

Nesse processo as características identificadas como vantagens do ambiente hospitalar, como o acesso rápido a tecnologias e atendimentos de intercorrência (WINGESTE; FERRAZ, 2008), não são simplesmente ignoradas por pacientes e familiares. De diferentes maneiras esses familiares e pacientes têm o potencia de interpretar e incluir em suas construções sociais essas vantagens e articulá-las com as suas historicidades, o que pode incluir o conhecimento sobre o cenário privilegiado da tecnologia médica com finalidades terapêuticas (PITTA, 1990).

Dessa maneira evidencia-se um contexto no qual pacientes e familiares constroem sentidos sobre o ambiente hospitalar em si. O hospital, ao mesmo tempo em que pode representar um espaço respeitado, pelo qual se sente apreço, gratidão e afeição, também pode representar um espaço em que pacientes e familiares são dependentes, frágeis e vulneráveis. Por outro lado, levar o paciente para o domicílio altera a rotina de toda a família (WINGESTE; FERRAZ, 2008). Nesse sentido, muitos cuidadores familiares abandonam profissões e empregos por não conseguirem conciliar as atividades (SILVA; ACKER, 2007), e assumem o cuidado no domicílio em uma jornada de trabalho sem princípio ou fim (SENA, 2006). 


\section{IMPLICAÇÕES SIMBÓLICAS NA ORGANIZAÇÃO DE UM HOME CARE: INTERPRETAÇÕES ENTRE A EQUIPE DE SAÚDE E OS CUIDADORES FAMILIARES}

A sobrecarga de trabalho dispensada ao responsável pelo cuidado de um familiar em domicílio implica impacto físico, social e emocional (MACHADO; FREITAS; JORGE, 2007). O modelo de assistência domiciliar exige lidar com desafios distintos dos modelos tradicionais de atendimento hospitalar. Ao se considerar o contexto de um atendimento de saúde domiciliar, pondera-se sobre aspectos fundamentais, como o paciente, a família, o contexto domiciliar, o cuidador e a equipe de saúde (DUARTE; DIOGO, 2005).

O paciente, em geral, é idoso, foco dessa modalidade de atendimento em virtude da necessidade de intervenção contínua dos serviços de saúde. Nesse processo, a família assume a responsabilidade do cuidado físico, financeiro e/ou emocional no domicílio. A despeito de, comumente, não possuir conhecimento técnico, há espaço para a família exercer uma lógica de poder microfísica, nos interstícios da rede de poder (SILVA, 2007). Isso ocorre na medida em que membros familiares passam a vivenciar o dia-a-dia dos profissionais da equipe de saúde em seu próprio domicílio. A produção e troca de signos levam a uma dinâmica na qual um sujeito está submetido às relações de poder e também exerce esse poder em suas práticas cotidianas (DREYFUS; RABINOW, 1995; FOUCAULT, 1999).

Tais manifestações de poder se legitimam tanto no convívio cotidiano familiar, quanto em instituições externas à família, com destaque para o poder judiciário. A judicialização da saúde tem sido realidade crescente nos dias atuais (MARQUES, 2008). Assim, isso ocorreria pelo fato de o Poder Judiciário não poder adiar, ou deixar sem resposta, casos urgentes relacionados à vida ou minimização do sofrimento do cidadão, levando-o a decisões consideradas trágicas e desnecessárias (MARQUES, 2008). A garantia do direito à saúde, caucionada pela Constituição Federal de 1988, atrelada ao emergencialismo das decisões, permitem aos familiares se utilizarem de manifestações intimidatórias no contexto familiar para exercer poder sobre a equipe.

A partir da análise das características desses diversos aspectos, observa-se que uma equipe de profissionais deve contextualizar e vislumbrar integralmente o paciente em assistência domiciliar para oferecer o sistema de cuidados necessários a ele (LACERDA; OLINISKI, 2005). Isso significa considerar também seus familiares, cuidadores e o contexto domiciliar em que se encontra.

Nessa ótica, a organização em questão, assim como as demais organizações contemporâneas, produz relações sociais e sistemas simbólicos que influenciam sujeitos 
envolvidos (PITTA, 1996). Portanto, para lidar com tais complexidades, considera-se a dinâmica dos sistemas simbólicos nos contextos organizacionais. O cuidado familiar encontra-se "mediado por ações e interações, contradições e conflitos, valores e sentimentos" (MARTINS, 2009, p. 560). Aspectos simbólicos que permeiam o dia-a-dia das famílias delineiam práticas sociais nas diferentes formas de cuidar.

\section{AS ORGANIZAÇÕES DE SAÚDE E O HOME CARE}

Estudar as organizações sob uma perspectiva simbólica permite entender que organizações são sistemas humanos que expressam padrões complexos de atividades culturais (MORGAN; FROST; PONDY, 1983). Na abordagem simbólica, símbolos resultantes das interações sociais e presentes no dia-a-dia de qualquer comunidade são interpretados para a compreensão de seus significados (CARRIERI; LEITE-DA-SILVA, 2007).

Símbolos e significados, produzidos e reproduzidos consciente ou inconscientemente, permeiam a construção social da realidade, influenciando-a e sendo influenciada por ela (GIOIA, 1986). A vida cotidiana apresenta-se como realidade interpretada pelos indivíduos e subjetivamente dotada de sentido (BERGER; LUCKMANN, 1978). Relacionamentos da vida humana envolvem características do cotidiano (TURNER, 1990). No caso das organizações, seu cotidiano evidencia dimensões que se estendem para além da formalidade (SARAIVA; CARRIERI, 2008). Contemporaneamente, tais elementos vêm despertando a atenção de pesquisadores e gestores, e a esfera simbólica ascende como temática de interesse na gestão.

Atualmente, no campo dos Estudos Organizacionais, as abordagens culturais vêm experienciando um ressurgimento, em que novas perspectivas divergem das abordagens seminais em alguns aspectos, como na atribuição de maior agência aos indivíduos e reconhecimento da permeabilidade das fronteiras culturais em relação aos que não participam diretamente de determinado grupo ou organização (WEBER; DACIN, 2011). Tais abordagens contribuem para que se conceba um papel mais ativo dos sujeitos na produção e reprodução de significados.

Destarte, evidencia-se a construção cotidiana do simbólico nas organizações (JOAQUIM, 2012), e, por constituir-se o indivíduo um ser social, suas construções simbólicas se inserem em representações não independentes entre si (GUARESCHI, 1995). Isso fica claro ao se observar o conceito de representações sociais (DOISE, 2002) como princípios que 


\section{IMPLICAÇÕES SIMBÓLICAS NA ORGANIZAÇÃO DE UM HOME CARE: INTERPRETAÇÕES ENTRE A EQUIPE DE SAÚDE E OS CUIDADORES FAMILIARES}

organizam relações simbólicas entre indivíduos e grupos compondo a realidade social. Interações humanas pressupõem representações, capazes de influenciar o comportamento do indivíduo em seu contexto social, ao mesmo tempo em que são construídas nas relações sociais (MOSCOVICI, 2003). Com base nesses entendimentos a concepção de representação aqui defendida se afasta da ideia de reprodução estática de parte da realidade, na direção de uma concepção na qual a representação faz parte da composição dinâmica da própria realidade no presente, na medida em que é interpretada e reinterpretada nos discursos nesse presente.

A referida concepção remete a uma visão da cultura também dinâmica. Nesse sentido, neste artigo, adota-se o entendimento da cultura como um sistema de símbolos entrelaçados, construídos socialmente, estabelecidos e interpretáveis, conforme defende Geertz (1989). Aqui temos uma visão de cultura com mais espaço para a compreensão da dinâmica de construção de sentidos no presente, na medida em que passado e presente se articulam. Não há preocupação em estabelecer uma origem ou uma essência no passado, mas reconhecer que esse último é articulado na dinâmica do presente. Ou seja, há espaço para considerar a história como algo em processo no presente, e não como uma origem estabelecida no passado e perenizada por ele para a reprodução de uma cultura.

Ao se assumir essa ótica neste artigo a cultura é inserida num contexto sócio-histórico, em contínua construção, que inclui as organizações e exige o reconhecimento de que os sujeitos em uma organização participam de outros grupos. Nesses grupos, o trânsito do indivíduo em diferentes instituições implica a apropriação de saberes específicos (CAVEDON, 2010), articulados simbolicamente na dinâmica cultural.

Ao se assumir essa visão dinâmica da cultura e da história, associada ao reconhecimento da produção de saberes específicos, viabiliza-se uma aproximação com as propostas de Foucault (2010) sobre as relações entre poder e saber e a produção simbólica a partir das práticas cotidianas. O poder se exerce por meio de saberes e discursos, tanto quanto o saber se constitui como "verdade" em determinado contexto histórico e social através de relações de poder. Enfim, o poder não é exterior à "verdade" dos saberes científicos (FOUCAULT, 2010). A partir disso, estabelecem-se relações de poder, que fazem parte das práticas cotidianas e permeiam as relações simbólicas. O conceito de poder adotado neste artigo prevê que o poder não é algo definido, identificável, localizável e manipulável, 
tratando-se de algo que se exerce e não que se possui (FOUCAULT, 1999). Entende-se que as relações de poder exercem-se através da produção e troca de signos em rede (DREYFUS; RABINOW, 1995).

Essas relações de poder são exercidas sobre cada sujeito, que também exerce poder sobre os outros (FOUCAULT, 2000). Assim, o poder não é entendido como propriedade, mas sim como relacional, não possuído em termos absolutos, mas exercido em práticas sociais. Dentro dessa concepção, as relações de poder são percebidas dinamicamente nas interações entre os sujeitos, de forma que não há grupos ou indivíduos que detenham o poder, mas sim que o exercem sob circunstâncias. Existem diferenças epistemológicas entre Foucault (1999, 2010), Moscovici (2003) e Berger e Luckmann (1978). Foucault não faz uma análise hermenêutica e nem acredita que existe uma relação determinante e unívoca entre significante e significado, evidenciando as contingências históricas e as descontinuidades discursivas que produzem significados finitos. Entretanto, apesar das diferenças epistemológicas entre Moscovici (2003), Berger e Luckmann (1978) e Foucault (1999, 2010), os autores têm como ponto comum o estudo das práticas sociais cotidianas e suas relações com o poder e o saber (FOUCAULT, 1999, 2010) e as representações que os sujeitos fazem destas práticas (MOSCOVICI, 2003; BERGER; LUCKMANN, 1978).

Nesse sentido, consideram-se os indivíduos analisados como inseridos em uma rede de relações que têm como espaço o lar da família mediado por simbolismos socialmente construídos. Em tais relações, os sujeitos não são vistos como detentores de poder, sejam familiares leigos (não conhecedores do campo da Medicina, mas cujo espaço simbólico é reconhecidamente familiar) ou profissionais de saúde (que dominam conhecimentos técnicos, mas atuam em um ambiente diverso daquele ao qual supostamente estariam habituados a exercer suas atividades). Nessa ótica, percebe-se uma dinâmica na qual múltiplos papéis se apresentam para os dois grupos, que se confundem em uma organização de saúde estabelecida no lar de uma família, na inserção da lógica familiar em uma organização de saúde.

As contribuições teóricas discutidas até aqui permitem articular a seguinte proposição: ocorre um hibridismo entre as lógicas dos profissionais de uma organização de saúde estabelecida no lar de uma família e de uma família inserida em uma organização de saúde, por meio de um processo oriundo de interferências a partir das interpretações de múltiplos aspectos simbólicos do contexto familiar e dos profissionais de saúde confrontados no cotidiano do home care. As práticas dos sujeitos fazem parte desse confronto e o refletem, em 


\section{IMPLICAÇÕES SIMBÓLICAS NA ORGANIZAÇÃO DE UM HOME CARE: INTERPRETAÇÕES ENTRE A EQUIPE DE SAÚDE E OS CUIDADORES FAMILIARES}

uma contínua reconstrução simbólica na rede de relações de poder que se estabelece no cotidiano do home care.

Com a finalidade de compreender essa proposição teórica à luz de evidências empíricas, o método da investigação realizada para os fins deste artigo é apresentado no próximo tópico.

\section{ASPECTOS METODOLÓGICOS}

A pesquisa empírica realizada baseou-se nos pressupostos do método qualitativo de investigação, marcado pelo caráter descritivo e pelo foco nos significados, no ambiente como fonte de dados e no pesquisador como instrumento para desvendar os fenômenos sociais (NEVES, 1996).

A coleta de dados foi realizada entre setembro e novembro de 2012, por meio de entrevistas semiestruturadas, baseadas em um roteiro, e grupos focais. As entrevistas e os grupos focais foram gravados mediante a autorização dos sujeitos. Foram considerados sujeitos da pesquisa os profissionais assistenciais de nível superior do home care de uma empresa de saúde privada, e os cuidadores familiares dos pacientes de internação domiciliar desse serviço.

As entrevistas foram realizadas com sete cuidadores familiares dos pacientes atendidos pelo home care na modalidade de internação domiciliar, identificados pelas letras $\mathrm{CF}$ (cuidador familiar), seguidas dos números de 1 a 7 . As entrevistas ocorreram nos domicílios dos pacientes, em locais reservados para a interação entre o pesquisador e o cuidador. Foram realizados três grupos focais, totalizando a participação de 27 profissionais, entre enfermeiros, médicos, psicólogo, assistentes sociais, nutricionistas, fonoaudiólogo e fisioterapeutas, identificados pelas letras GF (grupo focal), seguidas dos números de 1 a 3, e das letras iniciais de cada categoria profissional. Os grupos focais foram realizados com a moderação de uma psicóloga, além de dois observadores, e correram em um auditório externo ao local de trabalho desses profissionais, preparado especificamente para a realização dos grupos focais.

Após a transcrição das entrevistas e dos grupos focais, os dados obtidos foram agrupados e categorizados por meio da análise de conteúdo (BARDIN, 1977), através do 
modelo misto (LAVILLE; DIONNE, 1999). A partir do conjunto dessas categorias, os dados foram organizados da forma discutida a seguir.

\section{DIFERENÇAS ENTRE A ORGANIZAÇÃO DE UM HOME CARE E DO ATENDIMENTO HOSPITALAR}

Entre os familiares e os profissionais entrevistados, observou-se um consenso sobre a interpretação de que o atendimento domiciliar e o hospitalar seriam diferentes entre si. Cada uma das modalidades, segundo os pesquisados, apresentaria vantagens e desvantagens.

Foi destacada como vantagem da assistência domiciliar a disponibilização de conforto, envolvimento e o convívio do paciente com sua família e com outras pessoas de seu âmbito social. Em relação ao conforto, foi identificado que, para o familiar envolvido nos cuidados com o paciente, estar em casa seria mais confortável e menos desgastante, em contraposição à necessidade de estar presente no ambiente hospitalar, que demandaria idas e vindas de sua residência. Os trechos a seguir, manifestados pelos respondentes, ilustram esse entendimento.

\footnotetext{
E melhorou o quê? Que antigamente nós tínhamos a preocupação de estar indo pro hospital, vindo do hospital, levar roupa, trazer roupa, lavar, passar, levar, trazer. Aqui não, dentro de casa está aqui, eu pego a roupa dele e lavo, cuido das coisas dele, está aqui debaixo dos meus olhos. Está pertinho de mim, qualquer coisa já corro, né? (CF6).

A gente consegue ter uma vida com ela aqui em casa. Agora, no hospital, não. No hospital [...] eu tenho que ir pro hospital, eu tenho que fazer isso, tenho que fazer aquilo, porque tem que estar lá. Então, parou a sua vida no hospital. Tem que estar ali. Só ali. Aqui não, você pode ir na cozinha, você ali [...] Entendeu? Você vai no supermercado, volta, minha mãe está ali. Faz essas coisas normais. Em casa, quando está em casa, né? (CF1).
}

Ainda em relação ao conforto, um cuidador familiar, como se verifica no trecho abaixo, foi enfático ao afirmar que o ambiente hospitalar seria mais confortável para ele, mas não para o paciente. O familiar em questão considerava o fato de não precisar cuidar da casa, da alimentação, ou preocupar-se com os horários necessários para os cuidados com o paciente.

Pra mim, é um hotel o hospital, tá? Pra mim, o hospital é melhor. Mas para o paciente, não. Tá? Porque, aqui em casa, eu tenho que fazer tudo. Tenho que lavar, eu tenho que cozinhar [...] E, lá no hospital, não. [...] nós temos comida, nós temos tudo na mão, tudo no horário certo, né? E a gente fica sem fazer nada [...] (CF7).

Os profissionais atuantes na assistência domiciliar também identificaram o conforto da família ao manter o paciente hospitalizado, como pode ser constatado no trecho seguinte.

Então, quer dizer, o hospital dá essa falsa liberdade pra família. Porque,

REAd | Porto Alegre - Edição 83 - N 1 - Janeiro/Abril 2016 - p. 52-76 


\section{IMPLICAÇÕES SIMBÓLICAS NA ORGANIZAÇÃO DE UM HOME CARE: INTERPRETAÇÕES ENTRE A EQUIPE DE SAÚDE E OS CUIDADORES FAMILIARES}

deixando uma pessoa lá com o cuidador do hospital, o quê que ele vai fazer? Ele vai lá de visita (GF1 MED).

De acordo com os cuidadores familiares entrevistados, o envolvimento e o convívio social e familiar com o paciente foram destacados como questão propícia e favorável no atendimento domiciliar. Abaixo segue trecho que evidencia tal circunstância.

E em casa é melhor. Tem mais carinho [...] A família envolvida, mais envolvida com ele. Porque hospital não é todo mundo que tem disponibilidade de ir visitar (CF5).

Além dessa construção, que ocorre de maneira ambígua em relação aos cuidadores que associam o hospital a um hotel, também foi percebido, por diferentes sujeitos, que o ambiente hospitalar apresenta conotações simbólicas incompatíveis com sua associação a um local agradável. Como exemplo, apresentamos o excerto da fala de um respondente:

O ambiente hospitalar já é meio [...] É ruim [...] Ah, assim, quando você entra num hospital, o pessoal que tiver ali, ou está doente, ou está acontecendo alguma coisa errada. Então, no hospital, você não entra bom. Você não fica bom, você não vai passear em um hospital, né? Quando você está num hospital, é assim, por estar com algum problema. Então, o ambiente [...] É ruim (CF1).

Esse significado subjetivo dos hospitais sustenta outras interpretações, e, segundo um cuidador, também influencia a dinâmica de atuação dos profissionais que aí trabalham.

A maior diferença do atendimento no hospital e em casa, eu acho que é a falta de carinho dos enfermeiros, dos técnicos que estão, assim [...] Quando está na domiciliar, as pessoas tratam, não sei se é porque está na residência. Eu sei que o atendimento é melhor. Quando chega lá [no hospital], parece que eles estão tão habituados a já tratar as pessoas, já vê tantas pessoas doentes, tantas pessoas com dores, que parece que eles não ficam sensibilizados (CF3).

Aspectos interpretados como positivos no atendimento domiciliar prevaleceram nas falas dos entrevistados, apesar de se reconhecerem aspectos concretos de vantagem e diferencial do atendimento hospitalar, tais como a presença de profissionais médicos durante as 24 horas do dia e de suporte imediato diante de intercorrências clínicas. Isso pode ser conferido nas transcrições seguintes.

Porque, no hospital, quando ele estava ali, a diferença que existia era qual: Médicos 24 horas, né? (CF6).

Complementando também, que na UTI, no setor intensivo, o médico tá ali 24 horas. Então qualquer coisinha urgente, se alarmou o aparelho, tá ali (GF 1 ENF).

As falas de campo apontam que a mudança do ambiente hospitalar para o domiciliar implicaria em perda da tecnologia e práticas curativas, que seriam, por excelência, próprias do hospital (PITTA, 1990). Ressalta-se, portanto, a maior disponibilidade de tecnologias e atendimentos de intercorrência no ambiente hospitalar, em detrimento da individualidade da história do paciente, mais valorizada no domicílio (WINGESTE; FERRAZ, 2008). Nesse 


\section{Marianne Viana Borges, Alfredo Rodrigues Leite da Silva, Eloísio Moulin de Souza \&} Letícia Dias Fantinel

sentido, a assistência individualizada ao paciente atendido em domicílio também foi destacada como positiva. Nas instituições hospitalares, foi referido haver um número de profissionais entendido como insuficiente para o atendimento a todos os pacientes, no tempo desejado por pacientes e familiares. Já no atendimento ao paciente de internação domiciliar, a existência de um técnico de enfermagem exclusivo para um paciente é considerado proveitoso e benéfico. Ainda, destaca-se a humanização no atendimento ao paciente submetido a cuidados em domicílio. É interessante reconhecer que o espaço da casa tem significados que remetem ao familiar, à proteção, e tradicionalmente concebido, na cultura brasileira, como a esfera em que se dá a afetividade, e onde transitam apenas família e amigos (DAMATTA, 1997). Essa dimensão e significados, que facilitariam o desenvolvimento de vínculos e relações personalizadas, teriam sentido oposto ao hospital, que, fora do ambiente doméstico, representaria um espaço onde predominaria a impessoalidade e a indiferenciação (DAMATTA, 1997).

Essas manifestações e as demais apresentadas até aqui revelam construções que vão além da dimensão objetiva, pois, todo entendimento humano é simbólico (GIOIA, 1986). Símbolos têm conotações figurativas para estabelecer significado e importância e, apesar de construídos subjetivamente, tanto eles quanto seus significados são tratados como objetivamente reais (GIOIA, 1986).

Destarte, percebe-se que a interpretação sobre o serviço de assistência domiciliar pode variar entre os sujeitos envolvidos e seus contextos sociais. Por exemplo, o modelo de atenção domiciliar proporciona redução de riscos ao paciente (LACERDA, OLINISKI, GIACOMOZZI et al., 2006). Em consequência disso, o paciente vive mais tempo, se comparado ao atendido no hospital. Nos dados coletados, foi identificado que esse prolongamento da vida é perceptível aos familiares e aos profissionais. Entretanto, essa sobrevida dos pacientes atendidos em domicílio nem sempre é percebida como positiva pelos profissionais de saúde. Essa situação encontra-se elucidada nos trechos abaixo.

$\mathrm{Eu}$ adoro trabalhar aqui, mas gente, o doente custa muito em morrer. Ele não morre. Eu tenho paciente há 12 anos que está comigo [...] Eu não quero ir pra domiciliar não, eu quero morrer logo (GF1 MED).

Vou ver, é da domiciliar né? Aquele vovozinho, todo cheio de escara, todo ferradinho que vocês insistem em manter vivo, né? [tratando do que os colegas da UTI falam da domiciliar] (GF3 FISIO).

As diferentes interpretações apresentadas podem ser explicadas pela origem e pertencimento dos indivíduos a diferentes grupos sociais. Embora seja possível perceber 


\section{IMPLICAÇÕES SIMBÓLICAS NA ORGANIZAÇÃO DE UM HOME CARE: INTERPRETAÇÕES ENTRE A EQUIPE DE SAÚDE E OS CUIDADORES FAMILIARES}

alguma heterogeneidade nos discursos, no aspecto específico da sobrevida do paciente, vê-se em alguns profissionais a percepção dessa sobrevida como algo negativo. Ao entender-se que relações entre indivíduos e grupos se organizam a partir de suas construções simbólicas (DOISE, 2002), percebe-se que essas diferentes origens e pertencimentos interpõem-se no complexo processo de produção, reprodução e circulação das distintas representações sociais. Tais representações interferem nas atividades cognitivas e encontram-se profundamente imbricadas à realidade de cada ambiente social (MOSCOVICI, 2003). Considerando-se particularidades e singularidades de cada família e de cada paciente frente à realidade da doença, haverá diferentes formas de mudança na rotina dessa família e de suas práticas, em confronto com as práticas dos profissionais de saúde.

\subsection{Mudanças na dinâmica familiar na organização do home care}

O diagnóstico de uma doença tende a ser uma crise para as famílias, pois, geralmente, o paciente e a família não estão preparados para as mudanças decorrentes do processo de adoecimento, especialmente em acometimentos crônicos. Determinados diagnósticos simbolizam uma inadvertida relação com a morte, colocando o paciente em uma posição de extrema fragilidade (SONTAG, 1984). As doenças exigem novos modos de enfrentamento, modificações nas auto definições da família e períodos de adaptação (DUARTE; DIOGO, 2005). Quando um paciente é tratado em seu domicílio, mudanças ocorrem nesse ambiente, e as modificações se estendem às rotinas familiares já estabelecidas (WINGESTE; FERRAZ, 2008). Os dados analisados evidenciam, principalmente por tais mudanças, o processo tende a ser difícil para a família.

Dentre as mudanças evidenciadas nos dados coletados, foi identificada a perda da privacidade familiar dentro da residência. Essa privação à qual o cuidado de um parente doente submete seu cuidador familiar pode ser evidenciada na transcrição abaixo.

\footnotetext{
Porque às vezes a gente tem, assim, o momento da gente, de família. E, às vezes é complicado, você quer conversar, ou quer discutir e sempre tem alguém de fora na sua casa $(\mathrm{CF} 2)$.
}

A rotina de trabalho dos familiares cuidadores que assumem ter um paciente sendo tratado em domicílio também é abalada, inclusive com implicações que vão até ao abandono 


\section{Marianne Viana Borges, Alfredo Rodrigues Leite da Silva, Eloísio Moulin de Souza \&} Letícia Dias Fantinel

de suas profissões, para a plena dedicação ao paciente (SILVA; ACKER, 2007). Essa condição também foi identificada nas entrevistas realizadas, como se evidencia a seguir.

A [mãe do paciente] teve que abrir mão do emprego dela (CF4).

Ademais, a vida social desses familiares também é afetada, por conta da demanda de cuidados, vigilância e acompanhamento contínuos. As narrativas abaixo destacam tal situação.

Então quem está vivendo esse problema não tem mais vida, não pode sair de casa, tem que ter uma pessoa que cuide, se você sair (GF $1 \mathrm{ENF}$ ).

Então acaba assim, você não tendo vida social e nem nada (CF1).

Não só a vida social do familiar sofre prejuízo ao manter-se um paciente em casa, como também o relacionamento conjugal pode ser afetado, como mencionado abaixo:

Mas é assim, essa rotina [...] Entendeu? Ela (a esposa) tá trabalhando hoje, eu estou em casa. À noite eu saio, ela chega. Amanhã, eu estou trabalhando, no outro [dia] ela está em casa, entendeu? (CF4).

O cuidado no domicílio implica uma jornada contínua com responsabilidades e tarefas diversificadas (SENA, 2006), sobrecarga percebida na fala dos entrevistados. Os familiares entrevistados também se mostraram afetados emocionalmente por ter em casa um parente dependente de cuidados, algo identificado em outros estudos (MACHADO; FREITAS; JORGE, 2007), e verificado na fala transcrita abaixo.

Se eu não tomar remédio pra controlar meu estresse do dia-a-dia, eu acho que eu nem estava viva mais, pelo que eu já passei (CF6).

Esse desgaste físico e emocional das famílias pode interferir em médio e longo prazo no cuidado com os pacientes. Os profissionais pesquisados destacaram a queda no desempenho assistencial dos cuidadores, quando estes permanecem por tempo prolongado nessa atividade.

Então todo mundo vai na residência pra orientar, treinar e educar essa pessoa que vai realizar os cuidados. Só que é uma rotina diária, é uma rotina cansativa, entendeu? Então, assim, às vezes a gente chega a um ponto que a gente não consegue mais desenvolver o trabalho [...] É uma família cansada, uma família desestruturada, com o desgaste do tempo. Âs vezes, inicia um trabalho muito bom, mas que vai se perdendo ao longo do tempo [...] (GF3 FISIO).

Os desafios de se ter um parente doente sendo cuidado em casa também pode atingir o âmbito econômico, tendo em vista a possível redução da renda familiar, aliada ao aumento de despesas.

Antes do acidente eu ganhava $\mathrm{X}$, depois do acidente, caiu, mas caiu com força $[\ldots]$ caiu por mais da metade a nossa situação financeira [...] (CF 2). 


\title{
IMPLICAÇÕES SIMBÓLICAS NA ORGANIZAÇÃO DE UM HOME CARE: INTERPRETAÇÕES ENTRE A EQUIPE DE SAÚDE E OS CUIDADORES FAMILIARES
}

\begin{abstract}
A gente têm famílias pobres, e se a gente botar na ponta do lápis quanto custa um paciente em casa, é difícil. É fralda, é medicação, energia elétrica. Aí o paciente tá acamado, tem a demanda de lavar roupa [...] o paciente com sonda, que não conseguiu ainda a dieta no SUS, tem que comprar e é caro (GF 2 ENF).
\end{abstract}

Aqui cabe destacar que a condição econômica da família influencia na maneira dos membros se relacionarem com as mudanças na dinâmica familiar. Enquanto uma família pobre tende a ter muitas dificuldades financeiras para lidar com o aumento de despesas e a redução na renda familiar, uma família de classe média alta tende a ter menos dificuldades para absorver essas demandas financeiras. Além disso, uma melhor condição financeira permite contratar profissionais adicionais que ajudam os membros familiares a terem um tempo para se dedicar a outras atividades profissionais e pessoais. Esse aspecto faz a diferença na percepção do que envolve o sentido de que os membros familiares não "têm mais vida" no home care.

\footnotetext{
Então quem está vivendo esse problema não tem mais vida, não pode sair de casa, tem que ter uma pessoa que cuide se você sair, não pode depender de um parente pra fazer um favor, você tem que contratar, então é muito gasto. Então, tudo isso vai depender de disponibilidade né? Que no fundo acaba em disponibilidade financeira principalmente (GF $1 \mathrm{ENF})$.
}

Ficou evidente que a condição financeira se apresenta como um aspecto mediador relevante do impacto nas relações familiares no home care. Deve ficar claro que a melhor condição financeira não se apresentou como algo que impede o impacto da mudança nas relações familiares, ela apenas interfere nele, aparentemente, de maneira positiva. Mas mesmo nessas famílias, assim como nas outras, o cuidado de um parente tendo o domicílio como cenário, ocasiona rupturas no contexto familiar até então vigente, na direção de uma nova construção contextual. Tal construção revela o caráter social e dinâmico do cuidado familiar (MARTINS, 2009). Esse processo envolve os simbolismos no dia-a-dia das famílias e demarca práticas sociais em seu seio.

O cuidar em home care envolve relacionamento entre família, paciente e profissionais de saúde, dentro de uma residência, locus que não pertence a todos os envolvidos. As construções sociais desenvolvidas pelas dificuldades decorrentes desse cuidado, aliadas às necessidades de aprimoramento assistencial do cuidador frente a uma nova realidade, evoca uma conexão social. Entende-se que, nesse vínculo social, expressam-se diferentes relações de poder. 


\subsection{Relações de poder entre a família e a esquipe profissional}

Relações de poder se exercem através da produção e da troca de signos, conduzindo condutas e ordenando probabilidades sobre sujeitos livres (DREYFUS; RABINOW, 1995). Dentro dessa ótica, nos dados analisados, foram identificadas relações de poder entre a equipe de saúde da assistência domiciliar e a família do paciente atendido nesse serviço, como apresentado abaixo.

Todos da equipe são um apoio e, assim, uma segurança que você tem que o negócio está indo bem, que está cuidando bem [...] Como você é leigo no assunto, vocês aí são experts, né? [...] Então, acaba que, como você não estudou, como você não sabe, então você tem que ter um apoio. Porque, se não, né? $\mathrm{E}$, assim, você tem medo de fazer coisa errada, né? (CF1).

Mas eles acabam colocando a gente como o porto seguro [...] a gente acaba entrando na família, e eles colocando na gente uma pessoa de referência pra eles, é uma segurança (GF3 ENF).

Relações entre poder e saber (FOUCAULT, 2010) são observadas no discurso de CF1. Desta forma, estabelece-se uma ordem do discurso na qual se atribui como sendo a única verdade possível o conhecimento científico adquirido por meio dos estudos universitários, negligenciando-se outras formas de saber, principalmente os saberes que os próprios cuidadores produzem ao conviverem e lidarem diariamente com os doentes.

Em contrapartida à ênfase no conhecimento profissional, a família também exerce poder sobre a equipe assistencial na rede de relações do cotidiano, o que corrobora a ideia de que relações de poder são exercidas sobre cada sujeito e esse mesmo sujeito exerce tal poder sobre os outros (FOUCAULT, 2000). A transcrição que segue evidencia isso no contexto investigado:

Mas, depois que a gente está lá na casa do doente, que a família se sente amparada por você entendeu? Vê você como um [...] como Deus e o diabo, se me permite a palavra, porque, por exemplo, se você não faz também aquilo que eles querem, eles se viram contra você, entendeu? (GF 1 MED).

Na prática, a equipe assistencial necessita do apoio da família para que o paciente se mantenha em estado clínico adequado, assim como a família depende da equipe. Nesse contexto, os indivíduos, consciente e inconscientemente, estão envolvidos por uma lógica recíproca de poder (SILVA, 2007). A família exerce esse poder de maneira sutil e microfísica 


\section{IMPLICAÇÕES SIMBÓLICAS NA ORGANIZAÇÃO DE UM HOME CARE: INTERPRETAÇÕES ENTRE A EQUIPE DE SAÚDE E OS CUIDADORES FAMILIARES}

sobre a equipe, visto que só foi mencionada tal dependência pelos profissionais e não pela família, como segue.

Mas, mesmo se fôssemos $100 \%$, nós dependemos muito dessa parceria com família [...] Então, se a gente fizer orientação e ela não for seguida, não vai adiantar. [...] eu vejo que a gente depende muito dessa parceria com família (GF 1 FISIO).

A facilidade de acesso a informações também fornece subsídios para que as famílias exerçam poder sobre a equipe de saúde; esses últimos se ressentiriam, assim, da perda do privilégio do controle do conhecimento profissional. $\mathrm{O}$ trecho a seguir revela essa relação.

Hoje existe uma falta de respeito muito grande com a equipe de saúde. Hoje todo mundo abre o google e então se sente apto a questionar algumas condutas suas e isso obriga a gente também, porque eu também entendo isso com um aprendizado, de ter uma firmeza absurda. Você tem que subir no banquinho e falar assim, 'não é isso', e peitar a família muitas vezes de uma forma, até chegar ao ponto de se discutir, que eu acho que é uma situação máxima, né? [...] Mesmo que fale bobagem, fale com firmeza, senão você é engolido por alguém da família [...] quem começa [na equipe] sofre pra caramba, como eu sofri. Isso não acontece só com a nutricionista [...] acontece com médico, enfermeiro, fisioterapeuta. Acontece com todo mundo (GF 1 NUTRI).

Fica claro que GF 1 Nutri utiliza-se de jogos de verdade (FOUCAULT, 2010) para impor seu discurso. Para isso, apoia-se em um saber considerado científico, revestido de neutralidade e fora dos jogos de poder (FOUCAULT, 2010). Tais dispositivos relacionam-se a aspectos simbólicos tangentes à maneira de falar com os familiares, não transpassando imagem de insegurança e dúvida, mesmo que existam.

Outra forma pela qual as famílias exercem poder sobre a equipe de saúde, é em relação às ameaças de pleito judicial, em um contexto de crescente judicialização da saúde (MARQUES, 2008). Os fragmentos abaixo revelam essa constatação.

Agora, qualquer coisa que a família pede e você fala não, não tem indicação, não precisa fazer. Mesmo porque, qualquer coisa, depois é advogado, é processo, é canetinha [...] (GF3 MED).

Mas você tem que saber conversar, porque, dependendo da família, se você fala "a", eles usam seu argumento pra entrar na justiça. (GF3 FONO).

Fica claro no contexto em questão que o poder é exercido em redes nas quais os indivíduos circulam e se encontram em posição de exercê-lo e de ser submetidos a ele (FOUCAULT, 1999). A extensão dessa rede fica clara quando se observa que o próprio cuidador familiar estabelece relações de poder em torno de seu papel com sua própria família, conforme indica a manifestação abaixo.

Mas você tem um instinto. Né? E sempre assim, na família, sempre um se sobressai, sempre um. Aí, aqui em casa, eles me elegeram [para ser o cuidador], como eu sei tudo. Mas eu não sabia de nada (CF1).

REAd | Porto Alegre - Edição 83 - N 1 - Janeiro/Abril 2016 - p. 52-76 
Ainda, identifica-se o exercício de relações de poder entre os membros da equipe assistencial, e entre a equipe assistencial e a equipe administrativa, principalmente no que tange à escassez de recurso humano e à sobrecarga de atividade de profissionais. Enfim, converge-se à ideia de que

\footnotetext{
[...] as relações de poder se enraízam no conjunto da rede social. Isto não significa, contudo, que haja um princípio de poder, primeiro e fundamental, que domina até o menor elemento da sociedade; mas que há, a partir desta possibilidade de ação sobre a ação dos outros (que é coextensiva a toda relação social), múltiplas formas de disparidade individual, de objetivos, de determinada aplicação do poder sobre nós mesmos e sobre os outros, de institucionalização mais ou menos setorial ou global, organização mais ou menos refletida, que definem forma diferentes de poder (FOUCAULT, 1995).
}

Sendo assim, compreende-se que articulações entre práticas e interpretações dos aspectos relacionados ao serviço de atendimento domiciliar à saúde são influenciadas por construções sociais das famílias e da equipe de saúde, em um hibridismo entre as lógicas do profissional deslocado do seu contexto hospitalar e do familiar deslocado do cotidiano do seu lar.

\section{CONSIDERAÇÕES FINAIS}

$\mathrm{Na}$ busca por responder como os simbolismos organizacionais envolvem a organização de um home care em torno das práticas dos cuidadores familiares e da equipe de saúde, a análise dos dados possibilitou identificar diferentes interpretações e significados na construção da realidade de cada indivíduo. Nesse sentido, em relação ao atendimento domiciliar / atendimento hospitalar foi possível constatar que as diferenças entre esses modelos de assistência, vantagens e desvantagens na percepção dos sujeitos envolvidos, apresentam-se de maneira ambígua, sem clara polaridade em termos de juízo de valor. O que se apresentou de maneira unívoca é que o atendimento domiciliar não se configura apenas como a simples mudança de local de atendimento do hospital para o domicílio. As práticas familiares no cotidiano do domicílio interferem na dinâmica dessa organização, que também afeta a família. Trata-se de uma organização atípica, na qual uma família e uma equipe profissional atuam em conjunto na residência familiar sem que se trate de uma empresa familiar ou profissional, é algo híbrido, uma organização profissional-familiar.

A ambiguidade presente nessa dinâmica envolve até mesmo valores sociais relacionados à discussão sobre o prolongamento da vida propiciado pelo home care ser 


\section{IMPLICAÇÕES SIMBÓLICAS NA ORGANIZAÇÃO DE UM HOME CARE: INTERPRETAÇÕES ENTRE A EQUIPE DE SAÚDE E OS CUIDADORES FAMILIARES}

percebido como algo positivo ou negativo. Ou seja, a conotação simbólica de vida entra em confronto com a de sobrevida precária manifestada por alguns profissionais de saúde, que a colocam como uma consequência negativa do home care. Essa interpretação, marcada por um inequívoco caráter controverso, sustenta parte de uma percepção de aspectos negativos associados ao serviço de home care, que extrapola o espaço do domicílio familiar.

Dentro dos limites do domicílio, os resultados apontaram para o impacto na família ao se ter um parente doente sendo assistido no lar. Esse impacto foi expresso principalmente pela perda da privacidade dentro da residência e por mudanças percebidas nos âmbitos social, conjugal, físico, emocional e financeiro da família, em especial em relação ao cuidador responsável. Contudo, é importante destacar que é necessário um cuidado especial para se pensarem as conclusões deste estudo para outros casos de doenças ou doentes, como, por exemplo, crianças e jovens que poderão exigir períodos prolongados de diferentes tipos cuidados intensivos e que não foram aqui abordados. Nesses casos, pode haver outras formas de simbolizar o tratamento domiciliar, o que não foi escopo deste artigo.

Diante de tais mudanças, perceberam-se novas construções sociais no seio da família. Essas construções, desenvolvidas pelas dificuldades decorrentes de alterações exigidas para o cuidado de um parente, aliadas às necessidades de aprimoramento assistencial do cuidador frente a uma nova realidade, evocam a inserção do membro familiar e do profissional de saúde em uma mesma rede de relações permeada pelo poder.

Concebendo o poder não como uma estrutura e sim como uma estratégia que se exerce através da produção e da troca de signos dentro da estrutura social, foi revelado que os envolvidos no processo de assistência domiciliar exercem e são submetidos a relações de poder. No ambiente do atendimento domiciliar, a equipe de saúde exerce poder sobre a família, por ser a detentora do conhecimento profissional que garante a segurança do atendimento. Em contrapartida, a família também exerce poder sobre a equipe de saúde. Tal relação de poder é identificada através da dependência que a equipe de saúde tem diante da família para a continuidade de suas atividades junto ao paciente. Também foi identificado que o pronto acesso a informações técnicas específicas através da rede mundial de computadores e a judicialização da saúde contribuem para o exercício do poder da família sobre a equipe assistencial.

REAd | Porto Alegre - Edição 83 - N 1 - Janeiro/Abril 2016 - p. 52-76 
Dentro dessa dinâmica de tensões, sinais e símbolos criados na história das pessoas envolvidas revelaram-se mutáveis, adaptáveis e influenciadores diante de uma nova rotina, o que confirma empiricamente a proposição inicialmente defendida, de que ocorreria hibridismo entre as lógicas dos profissionais e dos familiares, por meio de um processo oriundo de interferências a partir das interpretações de aspectos simbólicos do contexto familiar e dos profissionais de saúde confrontados no cotidiano do home care.

Tal hibridismo marca as variações e semelhanças encontradas nos elementos das práticas sociais dos diferentes sujeitos envolvidos no serviço de assistência domiciliar. A partir de sua constatação, como contribuição final deste artigo, sugere-se a realização de estudos para a investigação de lacunas sobre suas implicações no contexto do home care.

Dentre essas lacunas, ressalta-se a discussão da extensão da sobrevida dos indivíduos assistidos por um serviço de assistência domiciliar. É importante o aprofundamento da investigação desse cenário e suas implicações para a família cuidadora, para a equipe de saúde e para o paciente, principalmente quando este for capaz de expressar-se de forma lúcida e orientada. A manutenção de um paciente em sobrevida precária por longo tempo no domicílio surgiu neste estudo como preocupação dos profissionais de saúde. Entretanto, permanecem em aberto as implicações disso para a família, na medida em que ela assume o papel de, em parte, prover a organização que sustentará essa sobrevida, o que, como se viu, pode trazer conforto para uns e dor para outros, por um longo tempo, inclusive para o próprio paciente.

\section{REFERÊNCIAS}

BARDIN, L. Análise de Conteúdo. Lisboa: Edições 70, 1977.

BERGER, P.L.; LUCKMANN, T. A construção social da realidade. Petrópolis: Vozes, 1978.

CARRIERI, A.P.; LEITE-DA-SILVA, A. Aspectos simbólicos da gestão organizacional. In: JUNQUILHO, G.; BIANCO, M.; BEHR, R.; SOUZA, S. (Orgs.). Tecnologias de gestão: por uma abordagem multidisciplinar. Vitória: EDUFES, 2007. p.19-32.

CAVEDON, N.R. De frente pro crime: cultura organizacional e socialização dos peritos ingressantes no Departamento de Criminalística do Instituto-Geral de Perícias do Rio Grande do Sul. Revista de Administração Mackenzie, São Paulo, v. 11, n. 4, p. 38-65, jul./ago. 2010. 
IMPLICAÇÕES SIMBÓLICAS NA ORGANIZAÇÃO DE UM HOME CARE: INTERPRETAÇÕES ENTRE A EQUIPE DE SAÚDE E OS CUIDADORES FAMILIARES

DAL BEM, L.W.; GAIDZINSKI, R.R. Home care: planejamento e administração da equipe de enfermagem. São Paulo: Andreoli, 2007.

DAMATTA, R. A casa \& a rua: espaço, cidadania, mulher e morte no Brasil. Rio de Janeiro: Rocco, 1997.

DOISE, W. Da psicologia social à psicologia societal. Psicologia:Teoria e Pesquisa, Brasília, v. 18, n. 1, p. 27-35, jan./abr. 2002.

DREYFUS, H.; RABINOW, P. Michel Foucault, uma trajetória filosófica: para além do estruturalismo e da hermenêutica. Rio de Janeiro: Forense Universitária, 1995.

DUARTE, Y.A.; DIOGO, M.J. Atendimento domiciliário: um enfoque gerontológico. In: DUARTE, Y.A.; DIOGO, M.J. (Orgs.). Atendimento domiciliar: um enfoque gerontológico. São Paulo: Atheneu, 2005. p. 3-18.

ERDMANN, A.L.; MELLO, A.L.S.F; MEIRELLES, B.H.S.; MARINO, S.R.A. As organizações de saúde na perspectiva da complexidade dos sistemas de cuidado. Revista Brasileira de Enfermagem, Brasília, v. 57, n. 4, p. 467-471, jul./ago. 2004.

FOUCAULT, M. Em defesa da sociedade: curso no Collège de France. São Paulo: Martins Fontes, 1999.

FOUCAULT, M. Estratégia, poder-saber. Rio de Janeiro: Forense Universitária, 2010.

FOUCAULT, M. Estruturalismo e Pós-estruturalismo. In: FOUCAULT, M. Arqueologia das ciências e história dos sistemas de pensamento. Rio de Janeiro: Forense Universitária, 2000. p. 307-334.

FOUCAULT, M. O sujeito e o poder. In: RABINOW, P.; DREYFUS, H. (Orgs.). Michel Foucault, uma trajetória política: para além do estruturalismo e da hermenêutica. Rio de Janeiro: Forense Universitária, 1995. p. 231-249.

GEERTZ, C. Uma descrição densa: por uma teoria interpretativa da cultura. In: GEERTZ, C. A interpretação das culturas. Rio de Janeiro: Guanabara Koogan, 1989. p. 13-41. 
GENET, N.; BOERMA, W.G.W; KRINGOS, D.S.; BOUMAN A.; FRANCKE A.L.; FAGERSTRÖM C.; MELCHIORRE, M.G.; GRECO, C.; DEVILLÉ, W. Home Care in Europe: a systematic literature review. BMC Health Services Research, London, v. 11, p. 1$14,2001$.

GIOIA, D.A. Symbols, scripts, and sensemaking: creating meaning in the organizational experience. In: SIM, H.P.; GIOIA, D.A. (Eds.). The thinking organization. San Francisco: Jossey-Bass Publishers, 1986. p. 49-74.

GUARESCHI, P.A. "Sem dinheiro não há salvação": ancorando o bem e o mal entre os neopentecostais. In: GUARESCHI, P.A; JOVCHELOVITCH S. (Orgs.). Textos em representações sociais. Petrópolis: Vozes, 1995. p. 191-225.

JOAQUIM, N.F. A gestão (extra)ordinária do cotidiano. In: ENCONTRO NACIONAL DE ESTUDOS ORGANIZACIONAIS DA ANPAD. 7., 2012, Curitiba. Anais... Rio de Janeiro: ANPAD, 2012.

KERBER, N.P.C.; KIRCHHOF, A.L.C.; CEZAR-VAZ, M.R. Considerações sobre assistência domiciliária e suas aproximações com o mundo do trabalho na saúde. Caderno de Saúde Pública, Rio de Janeiro, v. 24, n. 3, p. 485-493, mar. 2008.

LACERDA, M.R.; OLINISKI, S.R. Familiares interagindo com a enfermeira no contexto domiciliar. Revista Gaúcha de Enfermagem, Porto Alegre, v. 26, n. 1, p. 76-87, abr. 2005.

LACERDA, M.R.; OLINISKI, S.R.; GIACOMOZZI, C.M. VENTURI, K.K.; TRUPPEL, T.C. As categorias da assistência domiciliar e a prática dos profissionais de saúde - pesquisa exploratório-descritiva. Online Brazilian Journal of Nursing, Niteroi, v. 6, n. 0, p. 1-11, jan. 2007.

LACERDA, M.R.; OLINISKI, S.R.; GIACOMOZZI, C.M.; TRUPPEL, T.C. Atenção à saúde no domicílio: modalidades que fundamentam sua prática. Saúde e Sociedade, São Paulo, v. 15, n. 2, p. 88-95, maio/ago. 2006.

LAVILLE, C.; DIONNE, J. A construção do saber: manual de metodologia da pesquisa em ciências humanas. Porto Alegre: Artmed; Belo Horizonte: Editora UFMG, 1999. 
MACHADO, A.L.G.; FREITAS, C.H.A.; JORGE, M.S.B. O fazer do cuidador familiar: significados e crenças. Revista Brasileira de Enfermagem, Brasília, v. 60, n. 5, p. 530-534, set./out. 2007.

MORGAN, G.; FROST, P.; PONDY, L. Organizational symbolism. In: PONDY, L.; FROST, P.J.; MORGAN, G.; DANDRIGE, T.C. (Eds.). Organizational symbolism. Connecticut: Jay Press, 1983. p. 3-35.

MARQUES, S.B. Judicialização do direito à saúde. Revista de Direito Sanitário, São Paulo, v. 9 , n. 2 , p. $65-72$, jul./out. 2008.

MARTINS, J.J.; NASCIMENTO, E.R.P.; ERDMANN, A.L.; CANDEMIL, M.C.; BELAVER, G.M. O cuidado no contexto domiciliar: o discurso de idosos/familiares e profissionais. Revista Enfermagem UERJ, Rio de Janeiro, v. 17, n. 4, p. 556-562, out./dez. 2009.

MOSCOVICI, S. O fenômeno das representações sociais. In: MOSCOVICI, S.

Representações Sociais: investigações em Psicologia Social. Petrópolis: Vozes, 2003. p. 29110.

NEVES, J.L. Pesquisa qualitativa: características, usos e possibilidades. Cadernos de pesquisa em Administração, São Paulo, v. 1, n. 3, p. 1-5, jul./dez. 1996.

PITTA, A.M.F. A equação humana no cuidado à doença: o doente, seu cuidador e as organizações de saúde. Saúde e Sociedade, São Paulo, v. 5, n. 2, p. 35-60, 1996.

PITTA, A.M.F. Hospital: dor e morte como ofício. São Paulo: HUCITEC, 1990.

SARAIVA, L.A.S.; CARRIERI, A.P. Simbolismo e Dinâmica nas Organizações. In: ENCONTRO NACIONAL DE ESTUDOS ORGANIZACIONAIS DA ANPAD. 5., 2012, Belo Horizonte. Anais... Rio de Janeiro: ANPAD, 2008.

SENA, R.R. O cotidiano da cuidadora no domicílio: desafios de um fazer solitário. Cogitare Enfermagem, Curitiba, v. 11, n. 2, p. 124-132, maio/ago. 2006.

SILVA, C.A.M.; ACKER, J.I.B.V. O cuidado paliativo domiciliar sob a ótica de familiares REAd | Porto Alegre - Edição 83 - No 1 - Janeiro/Abril 2016 - p. 52-76 
Marianne Viana Borges, Alfredo Rodrigues Leite da Silva, Eloísio Moulin de Souza \& Letícia Dias Fantinel

responsáveis pela pessoa portadora de neoplasia. Revista Brasileira de Enfermagem, v. 60, n. 2, p. 150-154, mar./abr. 2007.

SILVA, J.C.S. Foucault e as relações de poder: o cotidiano da sociedade disciplinar tomado como uma categoria histórica. Revista Aulas, Campinas, n. 3, p. 28-38, mar. 2007.

SILVA, K.L.; SENA, R.; LEITE, J.C.A.; SEIXAS, C.T.; GONÇALVES, A.M . Internação domiciliar no sistema único de saúde. Revista de Saúde Pública, São Paulo, v. 39, n. 3, p. 391-397, 2005.

SONTAG, Susan. A Doença como metáfora. Rio de Janeiro : Edições Graal, 1984.

TURNER, B.A. Introduction. In: TURNER, B.A (Ed.). Organizational Symbolism. New York: De Gruyter, 1990. p. 1-11.

WEBER, K.; DACIN, T. The Cultural Construction of Organizational Life. Organization Science, Catonsville, v. 22, n. 2, p. 287-298, mar./apr. 2011.

WINGESTE, E.L.C.; FERRAZ, A.F. Ser assistido pelo serviço de assistência domiciliar: uma rica experiência para o doente de AIDS e seu cuidador. Revista Mineira de Enfermagem, Belo Horizonte, v. 12, n. 1, p. 34-39, jan./mar. 2008. 